http://doi.org/10.15359/ree.12-1.3

\title{
LA CONCEPCIÓN DE “SER HUMANO” EN PABLO FREIRE
}

\author{
Roberto Pineda Ibarra \\ Director de la Escuela de Sociología, Universidad Nacional \\ Heredia, Costa Rica
}

Recibido 22 de febrero 2007• Aprobado 14 de marzo 2007

\begin{abstract}
Resumen: Este artículo analiza cómo concibe Pablo Freire, -un teórico de la educación con amplia trayectoria e influencia mundial, y con una gran contribución a lo que se conoce como pedagogía Alternativa. Dicha concepción se ha plasmado en varios libros, producto de su experiencia como educador.
\end{abstract}

Palabras clave: Ser humano, existencia, participación con el mundo, pedagogía liberadora.

\begin{abstract}
This article analizes how Pablo Freire, one of the main education theoreticians with broad trajectory and world influence and with a big contibution to what it is known as alternative pedagogy, conceives the human been and his participation in and with the world. He has built his conception on this matter through several publications, merged from his teaching practice.
\end{abstract}

Key words: Human been, existence, participacion with the world, emancipating pedagogy.

\section{LA INTERROGANTE POR LA EXISTENCIA}

El dilema existencial, abordado por W. Shakaspeare en el monólogo de su obra Hamlet: "Ser o no ser. He ahí el dilema..", ha sido preocupación permanente de los seres humanos. Este lleva a una reflexión profunda sobre el intento de las personas por desentrañar los misterios de su existencia. Cabe señalar que esta preocupación existencial está implícita o explícitamente presente en el hacer de los seres humanos, orientados por una concepción de ser humano particular, construida tanto cultural como socialmente. Encontramos esta concepción en la obra de los filósofos, historiadores, sociólogos, físicos, biólogos y pedagogos.

En este trabajo, se presenta cómo concibe Paulo Freire, desde su propuesta pedagógica, al ser humano. Toda práctica humana lleva implícita una concepción de ser humano y de mundo, el mismo Freire (1990) señala, refiriéndose a la educación: “...toda práctica educativa implica por parte

1 Director de la Escuela de Sociología, Universidad Nacional, Heredia, Costa Rica. Licenciatura en Sociología con Mención en Metodología, 1988, Universidad Nacional. Egresado del Doctorado en Estudios Latinoamericanos con énfasis en Pensamiento Latinoamericano, Universidad Nacional. 
del educador, una posición teórica. Esta posición, a su vez, implica una interpretación del hombre y del mundo..." (p. 63).

Mas, ¿qué implicación tiene esta necesidad e interés por comprender la concepción de ser humano en Freire? El objetivo de este ensayo es descubrir que ésta incide en la posición teórica que orienta el trabajo de Freire hacia el cambio, la libertad, la lucha constante, desde la pedagogía, por la vida.

Tal aproximación lleva a pensar en una reflexión existencial; por ello, recurro a dos filósofos que reflexionan sobre la problemática existencial: Gabriel Marcel y Teodoro Olarte, como base para el análisis de Freire. Por ejemplo, el filósofo costarricense Teodoro Olarte, plantea dos preguntas que considero importantes como guía para iniciar mi trabajo, y que me ayudarán a escudriñar las obra de Pablo Freire:

¿Por qué, con qué fin, el hombre se pregunta por el ser?

¿Qué espera el hombre del ser? (Olarte, 1974,p.50)

\section{EL PROBLEMA DEL “SER” EN FREIRE, PRIMEROS PLANTEAMIENTOS}

En su obra La Educación como práctica de la Libertad, Freire aborda el problema del "ser", desde su perspectiva cristiana, con el dilema de la constitución del "yo" frente al "no-yo". Este enfoque lo lleva a plantearse tanto el proceso de socialización y la cultura, como el ejercicio del poder.

Freire enfatiza que: “...es fundamental partir de la idea de que el hombre es un ser de relaciones y no sólo de contactos, no sólo está en el mundo sino con el mundo" (Freire, 1976, p. 28).

El ser humano no puede considerarse como un ser incluido (en), sino que a partir de su característica humana, de su conciencia, de su existencia y permanencia en el mundo, establece una relación que lo lleva a estar en y con el mundo, condición que es certificada por la praxis, como acción-reflexión, como trabajo que transforma no sólo el entorno natural, sino al ser humano. Sin embargo, existe un problema que es apuntado con preocupación por Freire: las relaciones entre los propios seres humanos y la inequidad de estas, situación que lleva a las relaciones de poder desiguales, en las cuales unos seres humanos someten a otros, y en ese sometimiento, se genera un proceso que lleva a la alienación, a la negación del propio ser, tanto de los dominadores como de los dominados.

Julio Barreiro en su nota de presentación en la obra La educación como práctica para la libertad, menciona que “...en la medida en que a algunas personas no se les permite existir para ellos sino para otros o en función de otros, aquellos que les vedan esa existencia independiente tampoco son genuinamente "seres para sí" (Barreiro, 1976, p. 15).

Una de las ideas que Freire sugiere, para romper con la relación de opresión de unos seres humanos sobre otros, es el proceso comunicativo; como vía para liberarse de la enajenación. Este proceso comunicativo es entendido como la posibilidad, de cada ser, de decir su palabra libre y críticamente, asumiendo con responsabilidad su participación en los procesos sociales.

Ante esta situación, indica que:

Una de las grandes -si no la mayor- tragedias del hombre moderno es que hoy, dominado por las fuerza de los mitos y dirigido por la publicidad organizada, ideológica o no, renuncia cada vez más, sin saberlo, a su capacidad de decidir. Está siendo expulsado de 
la órbita de las decisiones. El hombre simple no capta las tareas propias de su época, le son presentadas por una élite que los interpreta y se las entrega en forma de receta, de prescripción a ser seguida (Freire, 1974, p. 33).

La importancia de la posibilidad de decidir por sí mismo, es planteada aquí como la base de la posibilidad de ser de las personas. Aquellas que no pueden decidir por sí mismas no existen, no son; y por lo tanto, la lucha debe orientarse a posibilitar la capacidad de decisión de todos. Esto sólo puede lograrse, según Freire, con una educación que les permita a los seres humanos asumirse como tales. Por ello, critica que la educación sea el medio mediante el cual se acostumbre a la gente a recibir las recetas o las decisiones de otros. El ser está ligado a la capacidad de los seres humanos de pensar para decidir, y sólo es posible pensar libremente si se tiene la información adecuada para decidir. La existencia está caracterizada por una temporalidad; es decir, es histórica, y además, con una dimensión política, en la cual por el momento existe un espacio cerrado: unos pocos mandan sobre muchos.

En Pedagogía del oprimido, la situación con respecto al ser cambia, y se plantea el problema del "ser" como un asunto de percepción entre el ser como sujeto y no como objeto. La relación opresor/oprimido, de acuerdo con Freire, es una relación enajenante para ambos. La condición de humanidad sólo puede establecerse sin la enajenación: las relaciones basadas en la opresión deben desaparecer: "Ahí radica la gran tarea humanista e histórica de los oprimidos, liberarse a sí mismos y liberar a los opresores" (Freire,1975, p. 33).

Para que esta liberación ocurra, los oprimidos deben tener claro que: "Solo en la medida en que descubran que alojan al opresor podrán contribuir a la construcción de su pedagogía liberadora. Mientras vivan la dualidad en la cual ser es parecer y parecer es parecerse con el opresor, es imposible hacerlo" (Freire, 1975, p. 35).

En tanto sigan existiendo relaciones de dominación habrá deshumanización. Ningún ser humano puede "ser" mientras esta situación no varíe hacia relaciones abiertas en las cuales, todos tengan las mismas oportunidades de participación, de decisión, de pensarse y actuar según sus intereses, sin lesionar los de los demás. La condición de existencia la da el rompimiento con la enajenación, y al romper con esta, no sólo se liberan los oprimidos, sino que también se liberan los opresores, humanizándolos.

Para efectuar esta liberación, Freire propone emerger de ella y liberarse de su fuerza: “...lo que sólo es posible hacerlo a través de la praxis auténtica; que no es ni activismo ni verbalismo sino acción y reflexión" (Freire, 1975, p. 43).

Debe transformarse la realidad que permite tal situación ya que según Freire (1975):

...los llamados marginados, que no son otros sino que los oprimidos, jamás estuvieron fuera de. Dentro de la estructura que los transforma en "seres para otro". Su solución no está en el hecho de "integrarse", de "incorporarse" a esta estructura que los oprime, sino transformarla para que puedan convertirse en seres para sí (p. 76).

De ahí la necesidad de la liberación de la que hemos hablado en líneas anteriores, y que Freire (1975) concibe de la siguiente manera:

La liberación auténtica, que es la humanización en proceso, no es una cosa que se deposita en los hombres. No es una palabra más, hueca, mitificante. Es praxis, que implica la acción y la reflexión de los hombres sobre el mundo para transformarlo (p. 84). 
La reflexión sólo es posible en la medida en que todos tienen derecho a la palabra; la realidad ya no mediatizada por el dominador, sino por la propia praxis y la posibilidad de ser libres, pero no individualmente, sino en forma colectiva. La visión de Freire no es individualista, es comunitaria, inclusiva, ya que propone que los oprimidos liberan a los opresores, y con ello, se da la humanización de todos, haciendo posible la existencia, el "ser".

\section{EL ENCUENTRO CON EL OTRO}

La experiencia del exilio lleva a Freire a viajar por muchos rincones del mundo y a enfrentar realidades muy diversas, distintas a las de su Brasil natal. Dicha experiencia enriquece sus reflexiones y lo llevan a situarse frente al otro, a pensar la alteridad, a reconocerla y a partir de ahí, plantear nuevas cosas, como en el caso de su experiencia en Guinea Bissau.

En su libro Cartas a Guinea Bissau: apuntes de una experiencia pedagógica en proceso, aclarando aspectos sobre cómo se ha considerado el analfabetismo y a los analfabetas, Freire indica que la pedagogía tradicional los ha considerado como una especie de lacra social, pero que al plantearse la posibilidad de trabajar en la alfabetización, los analfabetas han sido considerados: "Objetos en el contexto general de la sociedad de clases - puesto que se les oprime y se les prohíbe el ser- los analfabetos continúan siendo objetos en el proceso de aprendizaje de la lectura y de la escritura" (Freire, 1977, p. 35).

Los analfabetas no son considerados como otros ni reconocidos como interlocutores, al igual que los oprimidos, por lo que se les impone el ser de acuerdo con la imagen que los dominadores fijan de ellos; lo anterior lleva a la imposición de una visión de mundo que no les es propia ni les corresponde histórica ni culturalmente. Lo central de esto es el problema del "ser", ya que para que el ser humano sea (exista) debe ser consciente, su condición de existencia se la brinda alcanzar este estado de conciencia, a partir de ser capaz de situarse y pensar el contexto histórico y cultural en el que vive. Para Freire: "Ser consciente no es, en esta hipótesis, una simple fórmula o un mero slogan. Es la forma radical de ser de los seres humanos, en cuanto seres que no sólo conocen, sino que saben que conocen" (Freire, 1977, pp. 35-36).

Para que pueda darse la situación de conciencia planteada por Freire, es necesario que los seres humanos sean dueños de su palabra, capaces de tomar distancia de su cotidianidad, para pensarla y analizarla desde su propia perspectiva sin estar mediatizados por una ideología enajenante, en el sentido de no depender, en su ejercicio de pensarse, de otros que les indiquen las pautas por seguir, sino definiendo ellos sus propias pautas de pensamiento basadas en su praxis, en su acciónreflexión, en su tarea de transformar el mundo.

Las preguntas que cabe son: ¿Cuál es esa praxis? ¿Qué la define? Es necesario indicar que la praxis nos refiere al conocimiento, el cual es el resultado de la acción del trabajo, y este, necesariamente, nos refiere a la realidad.

Realidad que debe ser aprendida, aprendizaje que se realiza por medio de la educación, tanto formal como no formal, y la que debe entenderse, de acuerdo con Freire, como una relación en la cual nadie educa a nadie, los hombres se educan entre sí, mediatizados por su mundo.

Este aprendizaje debe entenderse como un proceso de conocimiento que encierra una relación con el acto de leer, el cual se transforma en un acto más que de lectura alfabética. Freire lo refiere al acto de comprender al mundo, su concepción de lectura es amplia e implica la conciencia, reflexionar sobre nuestras propias acciones y sobre este reflexionar: "El auténtico acto de leer es un 
proceso dialéctico que sintetiza la relación existente entre conocimiento-transformación del mundo y conocimiento-transformación de nosotros mismos" (Freire, 1990, p. 17).

El "ser" se plantea de una forma más amplia en la cual su posibilidad de "ser" debe romper con una relación dominante/ dominado, en donde no basta no ser enajenado. No es sólo estar consciente, es saberse capaz de conocer la propia realidad y reflexionar sobre este conocer libremente. Esto lleva a otra situación: el ámbito del "ser" en Freire y refiere a la concepción tradicional de la realidad, dicotomizada en sujeto/ objeto, visión desde la que se fragmenta la realidad y que, por esta razón, se convierte en una limitante para su comprensión.

Para Freire (1990):

...la cuestión de las relaciones entre sujeto y objeto, conciencia y realidad, pensamiento y ser, teoría y práctica. Toda tentativa de comprensión de esas relaciones que se funde en el dualismo sujeto-objeto, negando así la unidad dialéctica que hay entre ellos, es incapaz de explicar en forma coherente esas relaciones. Al romper la unidad dialéctica sujeto-objeto, la visión dualista cae en la negación ya de la subjetividad, sometiéndola a los poderes de una conciencia que la crearía a su gusto, ya de la realidad de la conciencia, transformándola así en mera copia de la objetividad (p. 26).

El acto de conocer es un acto de estudio, y estudiar significa disciplina, sistematicidad, conciencia; es una relación y una lectura de la realidad que propicia que el ser humano efectivamente sea, ya que esa capacidad de conocer lo lleva a la autonomía: "El estudiar es una forma de reinventar, de recrear, de reescribir, tarea del sujeto y no del objeto" (Freire, 1990, p. 40).

La concepción de "ser humano" se torna cada vez más compleja en Freire, conforme avanza en sus experiencias educativas y reflexivas, integrando la necesidad de libertad, de democracia, el aprendizaje crítico, de conciencia sobre la realidad histórico-cultural, la posibilidad de una lectura del mundo y la disciplina en el estudio. Otro elemento importante en esta concepción del ser humano, es su condición de ser social, y bajo esta condición, el conocimiento es un producto.

De acuerdo con Freire (1990):

Conocer, que es siempre un proceso, supone una situación dialógica. No hay, estrictamente hablando un yo pienso, sino un nosotros pensamos. No es el yo pienso lo que constituye el nosotros pensamos, sino por el contrario es el nosotros pensamos lo que me permite pensar (p. 66).

La propuesta educativa queda definida como una educación para la libertad: “...la educación para la liberación es un acto de conocimiento y un método de acción transformadores que los seres humanos deben ejercer sobre la realidad" (Freire, 1990, p. 72).

Puede notarse la coherencia de esta concepción con todos los planteamientos sobre conciencia, conocimiento, comunidad, dialéctica y dialogicidad, presentes en la obra de Freire. En su libro: La naturaleza política de la educación, Cultura, poder y liberación, la afirmación anterior queda más clara con la siguiente cita, según Freire (1990):

...existir es un modo de vida propio del ser que es capaz de transformar, de producir, de decidir, de crear y comunicarse. Mientras que el ser que simplemente vive no es capaz de reflexionar acerca de sí mismo y de saberse viviendo en el mundo, el sujeto existente 
reflexiona acerca de su vida dentro del territorio mismo de la existencia y cuestiona su relación con el mundo (p. 86).

En otras palabras: "El hombre no sólo es un ser que sabe sino un ser que sabe que sabe" (Freire, 1990, p. 87).

Cabe destacar el hecho de que la concepción de Freire sobre el ser es dialéctica; es decir, no es una visión estática de la existencia; todo lo contrario, el ser tiene la característica de estar siendo en su participación de la transformación de su medio, en su relación con los demás seres humanos, en las relaciones intersubjetivas, en el accionar y, en el reflexionar, el ser humano está siendo, se constituye; por eso, el limitarle los espacios para que pueda desarrollar todo su potencial, cortarle la libertad, considerarlo objeto y no sujeto de la educación, conllevan a la negación de su existencia, de tener una conciencia para sí.

Es importante comprender que existen diversas visiones del mundo y que estas deben ser respetadas en tanto le permitan al ser humano "ser". El reconocer al otro en su especificidad y el respeto a la diferencia, son fundamentales en la concepción de "ser" freiriana.

\section{LA DISPOSICIÓN AL CAMBIO REVOLUCIONARIO}

Ante el dilema de la existencia enajenada, Freire sugiere la posibilidad del cambio revolucionario. Revolucionario en el sentido de cambiar las relaciones basadas en la enajenación, sin dogmatismos ni sectarismos, democrático, inclusivo y de reconocimiento de la pluriculturalidad y de la diferencia como características de la existencia del ser humano. La esperanza se torna en un importante motor de la lucha por el cambio: "La esperanza es una necesidad ontológica: la desesperanza que, perdiendo su dirección, se convierte en distorsión de la necesidad ontológica" (Freire, 1996, p. 8).

La esperanza se convierte en la base para posibilitar la construcción de la utopía, del inédito viable, como lo llama Freire.

La realidad como proceso dialéctico lleva una interpretación del ser que permite formular la posibilidad del cambio, de la transformación de la realidad para orientarla hacia relaciones sociales cualitativamente mejores, que superen las relaciones enajenantes que se originan en la dicotomía opresores/oprimidos, según Freire (1996):

No puedo comprender a los hombres y las mujeres más que simplemente viviendo, histórica, cultural y socialmente existiendo, como seres que hacen su "camino" y que, al hacerlo, se exponen y se entregan a ese camino que están haciendo y que a la vez los rehace a ellos también (p. 93).

Freire (1996) plantea esta concepción del mundo y del ser humano, reafirmando esa posibilidad revolucionaria, de esperanza, por la que define que:

Es por estar siendo este ser en permanente búsqueda, curioso, tomando distancia de sí mismo y de la vida que tiene; es por estar siendo este ser dado a la aventura y a la pasión de conocer, para lo cual se hace indispensable la libertad que, constituyéndose en la lucha por ella, sólo es posible porque, aunque programados, no estamos sin embargo determinados; es por estar siendo así por lo que hemos venido desarrollando 
la vocación para la humanización y que tenemos la deshumanización, hecho concreto en la historia, la distorsión de la vocación (p. 94).

La vocación por ser humanos, es una vocación por ser más, condición que es efectiva en la medida en que cada persona sea libre; es decir, autónoma y en su vivencia cotidiana ser capaces de transformarse en un ser cualitativamente mejor.

Este ser más, al que se refiere Freire (1996), permite tener una visión dialéctica del ser humano, como un ser que se hace constantemente, no estático ni acabado: "Al hablar del ser más o de la humanización como vocación ontológica del ser humano, no estoy cayendo en ninguna posición fundamentalista, por lo demás conservadora. De ahí que insista también en que esa vocación, en lugar de ser algo a priori de la historia, es por el contrario algo que viene constituyéndose en la historia" (p. 95).

Además, es reforzada su posición comunitaria ante la existencia de los seres humanos, pues como ya he indicado anteriormente, la posibilidad de ser, en Freire, es una posibilidad que sólo puede darse en cuanto todos los seres humanos cuenten con las condiciones necesarias para la existencia plena, con conciencia para sí. De acuerdo con esto, una sociedad organizada bajo relaciones de dominación y opresión, no puede ser un espacio adecuado para la verdadera existencia; por eso, su señalamiento: "No soy si tú no eres, y sobre todo, no soy si te prohíbo ser" (Freire, 1996, p. 95).

Para que los seres humanos puedan contar con las condiciones para su existencia, es preciso romper con toda organización social cuya estructura se base en la desigualdad entre los seres humanos. Este rompimiento debe llevarse a cabo mediante compartir sus ideas, sus sueños, sus esperanzas; construyendo socialmente el momento revolucionario, sin imposiciones de tipo dogmático y sectarias, pero con claridad ideológica y política que oriente el proceso hacia la libertad y la democracia sin mesianismos; es decir, conscientemente, reflexionando sobre la propia acción. Por ello, Freire (1996) indica que:

No dudaría en afirmar que, habiéndose hecho históricamente el ser más la vocación ontológica de mujeres y hombres, será la democrática la forma de lucha o de búsqueda más adecuada para la realización de la vocación humana de ser más....No es posible actuar a favor de la igualdad, del respeto a los demás, del derecho a la voz, de la participación, de la reinvención del mundo, en un régimen que niegue la libertad de trabajar, de comer, de hablar, de criticar, de leer, de discrepar, de ir y venir, la libertad de ser (p. 165).

La lucha revolucionaria debe darse por la democracia, entendida como los espacios que Freire menciona en la cita anterior, y que debe necesariamente acabar con las desigualdades entre los seres humanos.

\section{A MANERA DE SÍNTESIS}

La concepción de ser de Freire, entraña una visión comunitaria, amplia, en la cual el respeto a la diversidad cultural, la temporalidad, la reflexión sobre el proceso cognoscitivo, se convierten en parte de la existencia misma, en condición para ser. Es una visión además dialéctica en la que se concibe la existencia como algo que se hace constantemente, en un estar siendo, producto de la 
praxis humana, en la transformación de la naturaleza y en esta transformación la de los sujetos que participan de ella.

La negación de todo tipo de dogmatismo, como principio básico para alcanzar la revolución, es otro aspecto que se debe subrayar, está presente en el pensamiento de Freire. Tal situación lo lleva a postular en Pedagogías de la Autonomía, el carácter ético del compromiso del educador con una educación libertadora, la necesaria autorreflexión del educador sobre su trabajo y la coherencia entre su pensamiento y su actuar en el aula.

El ser solamente existe, en cuanto las condiciones sociales y materiales así lo permitan; esto es, en la medida en que se encuentre en un espacio donde tenga acceso real a la satisfacción de sus necesidades básicas, en el cual pueda expresarse libremente, con derecho a la discrepancia, con oportunidad de reflexionar sobre su praxis, en un entorno democrático que comprenda la pluriculturalidad como característica del ser humano y no como defecto.

El ser, es una condición del ser humano en tanto que sea colectiva, dialéctica; el ser humano está siendo día con día; tiene por vocación ser más, reafirmar la humanización, no el negarla, creando y recreando las condiciones espirituales y materiales a efecto de alcanzar una sociedad democrática que permita la participación de todas y todos sin exclusiones, que tenga una educación liberadora, en busca de constituirnos en mejores seres humanos.

\section{REFERENCIAS}

Farré, L. (1968). Antropología Filosófica. El hombre y sus problemas. Madrid, España: Ediciones Guadarrama.

Freire, P. (1975). Pedagogía del oprimido ( $14^{\circ}$ ed. ). México: Siglo XXI Editores.

Freire, P. (1976). La educación como práctica de la libertad (17 a ed.). México: Siglo XXI Editores.

Freire, P. (1977). Cartas a Guinea Bissau: apuntes de una experiencia pedagógica en proceso. México: Siglo XXI Editores.

Freire, P. (1990). La importancia de leer y el proceso de liberación (7 ed.). México: Siglo XXI Editores.

Freire, P. (1990). La Naturaleza política de la educación. Cultura, poder y liberación. España: Ediciones Paidós.

Freire, P. (1992). Pedagogía de la esperanza: un reencuentro con la pedagogía del oprimido. México: Siglo XXI Editores.

Freire, P. (1996). Cartas a Cristina. Reflexiones sobre mi vida y mi trabajo. México: Siglo XXI Editores. 
Freire, P. (1997). Pedagogía de la autonomía. Saberes necesarios para la práctica educativa. México: Siglo XXI Editores.

Gabriel, M. (1964). El misterio del Ser. Buenos Aires, Argentina: Editorial Sudamericana.

Olarte, T. (1974). El ser y el hombre. San José: Editorial Fernández Arce. 